\title{
The influence of interdental spacing on the detection of proximal caries lesions in primary teeth
}

\section{Tatiane Fernandes Novaes Ronilza Matos \\ Paula Celiberti \\ Mariana Minatel Braga \\ Fausto Medeiros Mendes}

Department of Pediatric Dentistry, School of Dentistry, University of São Paulo, São Paulo, SP, Brazil.
Declaration of Interests: The authors certify that they have no commercial or associative interest that represents a conflict of interest in connection with the manuscript.

Corresponding Author:

Tatiane Fernandes Novaes

E-mail: tatifn@usp.br

Received for publication on Feb 24, 2012 Accepted for publication on May 10, 2012

\begin{abstract}
The aim of this study was to investigate the influence of interdental spacing on the performance of proximal caries detection methods in primary molars. In addition, aspects related to temporary tooth separation with orthodontic separators were evaluated. The proximal spaces between the posterior primary teeth $(\mathrm{n}=344)$ of 76 children $(4-12$ years old) were evaluated before and after temporary separation. Stainless steel strips with different standardized thicknesses were used to measure the presence of biological spacing and the spacing obtained after temporary separation with orthodontic rubber rings. First, the presence of proximal caries lesions was assessed by visual inspection, bitewing radiographs and a pen-type laser fluorescence device (DIAGNOdent pen). Visual inspection after temporary separation with separators was the reference standard method in checking the actual presence of caries. Multilevel analyses were performed considering different outcomes: the performance of the methods in detecting caries lesions and the spacing after temporary separation. The spacing did not influence the performance of the caries detection methods. The maximum spacing obtained with temporary tooth separation was $0.80 \mathrm{~mm}$ (mean \pm standard deviation $=0.46 \pm 0.13 \mathrm{~mm}$ ). The temporary separation was more effective in the upper arch and less effective when an initial biological interdental spacing was present. The biological interdental spacing does not influence the performance of proximal caries detection methods in primary molars, and temporary tooth separation provides spacing narrower than $1.0 \mathrm{~mm}$.
\end{abstract}

Descriptors: Diagnosis; Dental Caries; Tooth, Deciduous.

\section{Introduction}

Tight contact points between the proximal surfaces of the primary molars could be associated with an increased risk of the presence and activity of proximal caries, ${ }^{1-3}$ as the initiation and progression of proximal caries lesions are related to higher plaque accumulation in these conditions. ${ }^{4}$ In certain quadrants of the primary dentition, the presence of spaces is typical, particularly in Baume type I dental arches. ${ }^{2,5}$ However, proximal caries is more frequent in children with Baume type II arches. ${ }^{5}$

Since closed proximal spaces in the primary teeth are strongly correlated with caries occurrence, different methods of caries detection have been studied. ${ }^{3,6,7}$ Contact points hamper direct visual inspection of 
caries lesions in the primary molars; therefore, radiographs and fluorescence methods have been employed to assist dentists in detecting proximal caries lesions more sensibly. ${ }^{3,8,9}$ Another viable alternative is separating the teeth temporarily using orthodontic rubber rings. ${ }^{10}$ Many authors have suggested that this method promotes a spacing from 0.2 to $1 \mathrm{~mm},{ }^{10-13}$ but no previous study has evaluated the separation efficacy.

Although several reports have been published concerning the performance of different methods in detecting proximal caries lesions in the primary teeth, ${ }^{3,6-8,14}$ the influence of interdental spacing on the performance of these methods has not yet been studied. Moreover, associated factors related to the efficacy of temporary separation in the primary teeth require further studies to evaluate the benefits of this method.

Therefore, we aimed to investigate the influence of biological interdental spacing on the performance of different methods in detecting proximal caries lesions in the primary teeth. Furthermore, we also evaluated the efficacy of temporary tooth separation and its associated factors.

\section{Methodology}

This study was approved by the local Committee for Ethics in Research. Written informed consent was obtained from all of the children's parents or legal guardians prior to the evaluations. Thus, 76 children seeking dental treatment at School of Dentistry of University of São Paulo were randomly selected using the enrollment or history form of each child, without access to their oral health condition. The recruited subjects had at least one primary molar in contact with the adjacent tooth. The contact points of interest were on the distal surfaces of the first primary molars, the mesial surfaces of the second primary molars and the distal surfaces of second primary molars, only if the first permanent molar was present. The mesial surfaces of the first primary molars were excluded because of the common presence of space in these sites. Teeth with frank proximal cavitations or restorations (absence of marginal ridge) and hypoplastic defects were also excluded. Finally, 344 proximal sites were evaluated. All of the participants who presented a need for restorative treatment attended the Dental Clinic of our school. Preventive measures (diet and oral hygiene instructions) were also performed for all of the children.

Concerning the presence of proximal caries lesions, all of the surfaces of interest were assessed in individual clinical sessions using a pen-type laser fluorescence device (LFpen), the DIAGNOdent pen (Kavo, Biberach, Germany), visual inspection and radiographic methods, applied in a randomized order. Graduate students with experience in caries diagnosis conducted all of the examinations in all of the children. The methods and their performances in detecting proximal caries lesions, the training of the examiners and the calibration process were previously described in greater detail. ${ }^{3}$

The examiners used the International Caries Detection and Assessment System (ICDAS) for the visual inspection. ${ }^{15}$ For the radiographic examinations, bitewing radiographs were taken from each side (two radiographs for each child) with bitewing holders (Jon Han-Shin PF 682, Jon Ind., São Paulo, Brazil). Kodak Insight radiographic films $(22 \times$ $35 \mathrm{~mm}$, Eastman Kodak, Rochester, USA) were used. If the child did not accept the holder, a bitewing was constructed using adhesive tape. A probe tip 1 (for approximal surfaces) of LFpen was used for the measurements according to the manufacturer's instructions. The higher value of the two measurements of each proximal surface was recorded for statistical analyses.

All of the methods were individually performed. For the visual inspection, the cut-off point to indicate the presence of caries lesion was a score of 1 from ICDAS. For the radiographic method, radiolucency visible in the enamel was classified as the presence of caries lesions. For the LFpen method, the best cut-off point to indicate the presence of caries lesion was 6 , as determined in a previous study. ${ }^{3}$

After using the different caries detection methods, stainless steel strips (Coraldent, São Paulo, Brazil) with different standardized thicknesses $(0.10$, $0.20,0.25,0.30,0.40$ and $0.50 \mathrm{~mm}$ ) were used to measure the biological spacing. Then, orthodontic rubber rings with a thickness of $4 \mathrm{~mm}$ (Morelli, Sorocaba, Brazil) were placed around the selected 
contact points for 7 days. In case of the loss of the rubber, this procedure was repeated. The spacing obtained after the elastomeric separation, immediately after the removal of the rubber rings, was also assessed. If the proximal spacing was greater than $0.50 \mathrm{~mm}$, two or more steel strips were combined, and their thicknesses were summed. Subsequently, two examiners (RM and TFN) assessed the surfaces to detect the presence of caries lesions (non-cavitated or cavitated), and this evaluation was considered to be the reference standard method.

Several series of multilevel analysis were performed. First, we evaluated the influence of the biological interdental spacing on the performance of the proximal caries detection methods. The exploratory variable was the presence of biological proximal spacing with no temporary separation (dichotomous variable; no spacing versus with spacing). The outcomes were the proportions of false positive (with true negative as a reference) and false negative (with true positive as a reference) determinations obtained with the different methods separately (visual inspection, radiographic and LFpen methods). For these analyses, multilevel logistic regression was conducted, and the odds ratios (ORs) and $95 \%$ confidence intervals $(95 \%$ CIs) were calculated. Multilevel analysis was employed because the caries detection methods are performed in each proximal surface (first level), but the spacing is associated with two surfaces (level 2).

Subsequently, multilevel linear analysis was performed, the outcome of which was the spacing obtained after temporary separation (in $\mathrm{mm}$ ). The explanatory variables related to the child (second level) were age (in years), dentition (primary or mixed) and gender (male or female). The variables related to the proximal space (first level) were arch (upper or lower), spacing before separation (in $\mathrm{mm}$ ) and site (between $1^{\text {st }}$ and $2^{\text {nd }}$ primary molars and between $2^{\text {nd }}$ primary molar and $1^{\text {st }}$ permanent molar). The regression coefficients $(\beta)$ and standard errors (SE) were evaluated. For all of the analyses, we used MLwiN 2.10 software (Centre for Multilevel Modeling, Bristol, UK), and the level of significance was set at $5 \%$.

\section{Results}

A total of 76 children (32 males and 44 females) aged 4-12 years (mean \pm standard deviation [SD] $=7.4 \pm 1.6$ years old) participated in the study. The mean \pm SD of the dmf-t plus of these children was $3.82 \pm 4.43$ (range $=0$ to 20 ).

Most of the proximal sites included in our study (94.2\%) did not present biological spacing (Table 1). The teeth that presented a wider biological spacing were mostly found in the upper arch $(\mathrm{OR}=2.93$; $95 \% \mathrm{CI}=1.00$ to $8.57 ; \mathrm{p}=0.049$ ).

With respect to the performance of the methods, 102 surfaces were considered to be sound, and 418 were considered to harbor caries lesions (white spot or cavitated caries lesions) using the reference standard method. Independent of the presence of spacing, the false positive and false negative rates obtained with visual inspection were $25.5 \%$ and $33.3 \%$, respectively. With the LFpen method, the false positive rate was $17.6 \%$, and the false negative rate was $70.8 \%$, and for the radiographic method, the false positive and false negative rates were $2 \%$

Table 1 - Distribution of biological proximal spacing assessed before temporary separation between $1^{\text {st }}$ and $2^{\text {nd }}$ deciduous molars (DM) or between $2^{\text {nd }} \mathrm{DM}$ and $1^{\text {st }}$ permanent molars (PM) in upper and lower dental arches.

\begin{tabular}{|c|c|c|c|c|c|}
\hline \multirow{2}{*}{$\begin{array}{l}\text { Spacing } \\
(\mathrm{mm})\end{array}$} & \multicolumn{2}{|c|}{ Lower arch } & \multicolumn{2}{|c|}{ Upper arch } & \\
\hline & $\begin{array}{c}1^{\text {st }} \text { and } \\
2^{\text {nd }} D M s\end{array}$ & $\begin{array}{c}2^{\text {nd }} D M \\
\text { and } 1^{\text {st }} P M\end{array}$ & $\begin{array}{c}1^{\text {st }} \text { and } \\
2^{\text {nd }} \mathrm{DMs}\end{array}$ & $\begin{array}{c}2^{\text {nd }} D M \\
\text { and } 1^{\text {st }} P M\end{array}$ & Total (\%) \\
\hline 0.0 & 83 & 82 & 84 & 75 & $324 \quad(94.2)$ \\
\hline 0.1 & 2 & 2 & 5 & 6 & $15 \quad(4.3)$ \\
\hline 0.2 & 1 & 0 & 1 & 0 & $(0.6)$ \\
\hline 0.3 & 0 & 0 & 0 & 1 & $(0.3)$ \\
\hline 0.4 & 0 & 0 & 2 & 0 & $2 \quad(0.6)$ \\
\hline Total & 86 & 84 & 92 & 82 & 344 (100.0) \\
\hline
\end{tabular}


and $80.4 \%$, respectively.

When the influence of the presence of biological interdental spacing was considered in the analysis, we did not observe any statistically significant influence in either the false positive and false negative results (Table 2). The proportion of false negative or false positive results did not significantly decrease (or increase) with wider interdental spacing.

With regard to the efficacy of temporary separation, the mean \pm standard deviation of space obtained after temporary separation was

Table 2 - Influence of initial proximal spacing on the performance of different methods in detecting proximal caries lesions in terms of false positive (true negative as reference) and false negative (true positive) results.

\begin{tabular}{|c|c|c|}
\hline & $\begin{array}{c}\text { False positive results } \\
\text { odds ratio }\end{array}$ & $\begin{array}{c}\text { False negative results } \\
\text { odds ratio }\end{array}$ \\
\hline Visual inspection & 0.55 (0.05 to 5.91$)$ & 1.42 (0.51 to 3.95) \\
\hline $\begin{array}{l}\text { Laser fluorescence } \\
\text { device }\end{array}$ & 0.83 (0.09 to 7.66$)$ & 1.94 (0.59 to 6.42) \\
\hline $\begin{array}{l}\text { Bitewing } \\
\text { radiographs }\end{array}$ & $*$ & 0.95 (0.27 to 3.35$)$ \\
\hline
\end{tabular}

* Analysis not performed due to absence of false positive results obtained with radiographic method in surfaces with initial spacing. Figures in parenthesis are $95 \%$ confidence intervals.
$0.46 \pm 0.13 \mathrm{~mm}$. The maximum spacing obtained was $0.8 \mathrm{~mm}$, but this value was only found in two surfaces (Figure 1). Temporary separation was more effective in upper arches $(\mathrm{p}<0.001)$, but it was less efficacious when an initial biological proximal spacing was present $(\mathrm{p}<0.001)$ (Table 3$)$.

\section{Discussion}

The occurrence and detection of caries lesions has been relatively less studied in the primary dentition than in the permanent dentition. ${ }^{1,6}$ The absence

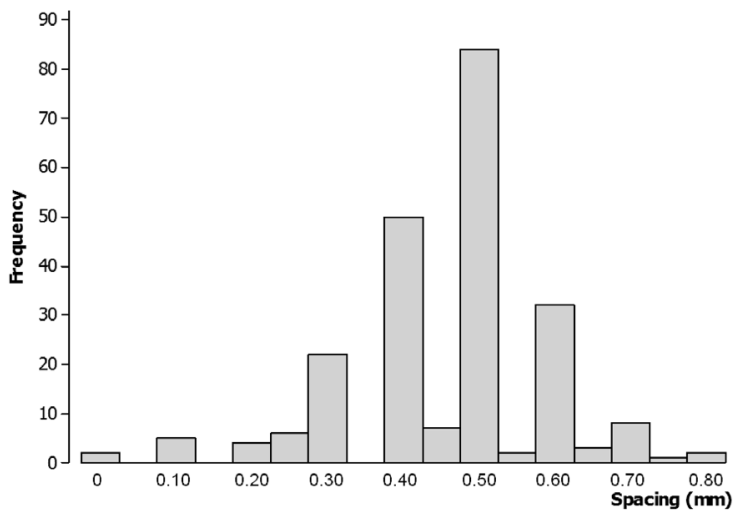

Figure 1 - Distribution of proximal spacing in primary molars assessed after temporary separation.
Table 3 - Factors associated with proximal spacing obtained after temporary separation with orthodontic rubber.

\begin{tabular}{|c|c|c|c|c|c|c|}
\hline \multirow[b]{2}{*}{ Independent variables } & \multicolumn{3}{|c|}{ Univariate linear regression } & \multicolumn{3}{|c|}{ Multiple linear regression } \\
\hline & $\beta$ & $\begin{array}{l}\text { Standard } \\
\text { error }\end{array}$ & $p$ & $\beta$ & $\begin{array}{l}\text { Standard } \\
\text { error }\end{array}$ & $p$ \\
\hline \multicolumn{7}{|c|}{ Variables related to the child } \\
\hline Gender (ref.: male) & & & & $*$ & & \\
\hline Female & 0.016 & 0.024 & 0.519 & & & \\
\hline Age (in years) & -0.005 & 0.008 & 0.489 & $*$ & & \\
\hline Dentition (ref.: primary) & & & & * & & \\
\hline Mixed & -0.007 & 0.045 & 0.869 & & & \\
\hline \multicolumn{7}{|c|}{ Variables related to the surface } \\
\hline \multicolumn{7}{|l|}{ Arch (ref.: lower) } \\
\hline Upper & 0.064 & 0.015 & $<0.001$ & 0.085 & 0.014 & $<0.001$ \\
\hline $\begin{array}{l}\text { Spacing before separation } \\
\text { (in } \mathrm{mm} \text { ) }\end{array}$ & -1.171 & 0.176 & $<0.001$ & -1.367 & 0.168 & $<0.001$ \\
\hline $\begin{array}{l}\text { Site (ref.: between } 1^{\text {st }} \text { and } \\
2^{\text {nd }} \text { primary molars) }\end{array}$ & & & & $*$ & & \\
\hline $\begin{array}{l}\text { Between } 2^{\text {nd }} \text { primary and } \\
1^{\text {st }} \text { permanent molar }\end{array}$ & 0.004 & 0.017 & 0.805 & & & \\
\hline
\end{tabular}

* Variables not included in the multiple model. $\beta=$ Coefficient regression. 
of biological spacing between the proximal surfaces of the primary molars is associated with higher caries prevalence. ${ }^{4,16-18}$ However, the detection of caries lesions at these surfaces can be difficult when tight contact points are present. ${ }^{3,19}$ Several methods have been proposed to aid the clinicians in reaching a better diagnosis and treatment decision at proximal surfaces, including visual inspection, radiography, fluorescence-based methods and temporary separation with orthodontic rubbers. However, the influence of biological interdental spacing on the performance of these methods and the efficacy of temporary tooth separation in children have not yet been studied.

Open contact points would be less susceptible to proximal caries lesions development than closed ones because they are more likely to be self-cleansing or adequately cleaned with tooth brushing and the correct use of dental floss. ${ }^{1}$ In contrast, the diagnosis and management of problems associated with restricted access to the proximal area due to contact points can vary with the experience of the professionals. Certain discrepancies could be attributed to different samples or different methodologies. ${ }^{14,20}$ Our results, however, demonstrated that the presence of proximal spacing did not influence the performance of proximal caries detection methods. Most likely, this finding reflects the fact that most of the proximal sites included in our study did not present wide biological spacing.

Nevertheless, closed proximal contact points could hinder the differentiation between white spots and cavitated lesions. ${ }^{3,10,11}$ This problem could be minimized using temporary tooth separation, which has been widely used in clinical practice and is a non-destructive, reversible and inexpensive technique. ${ }^{12}$ The acceptability of this method to children was also demonstrated in previous studies..$^{12,14,21}$ In contrast to the benefit of the possibility of distinguishing non-cavitated and cavitated caries lesions after temporary separation, occasional discomfort provoked by the placement of the rubber rings and the requirement for two appointments are disadvantages of the method. ${ }^{10,14,22}$ With regard to the discomfort, however, we observed that the method presented levels of discomfort similar to those of the
LFpen and radiographic methods. ${ }^{23}$

With regard to the use of temporary tooth separation as a diagnostic aid in pediatric dentistry, a period of one week works well and is administratively convenient. ${ }^{3,10,13}$ A separation of 0.2 to $1 \mathrm{~mm}$ has been reported, ${ }^{10-13}$ but we did not obtain a 1-mm spacing. To the best of our knowledge, only one study measured the efficacy of temporary tooth separation, demonstrating a maximum spacing of $0.2 \mathrm{~mm}$ created by the use of different elastomeric separators in permanent teeth. ${ }^{24}$ In our study, conducted in children with mixed dentition, ${ }^{1}$ we observed a mean spacing of $0.46 \mathrm{~mm}$, with the maximum spacing of $0.8 \mathrm{~mm}$ obtained in only two cases. We believe that this space allows the use of a WHO periodontal probe to sound the surface, enabling the correct diagnosis of the surface.

Regarding the use of temporary separation to validate the diagnostic methods, it is a typical reference standard for in vivo studies, although it is not a perfect one. However, dental separation is more difficult in permanent teeth, which are firmly anchored in alveolar bone. ${ }^{5,25}$ In deciduous teeth, this validation method can be useful. Higher values of reliability and a viable differentiation between the presence of white spot lesions and that of cavitations were found. ${ }^{3,14}$ In addition, the reference standard used in our study is closer to patient relevance, permitting to increase the clinical applicability of the study. ${ }^{26}$

With respect to the associated factors, the temporary separation was more effective in the upper arch, likely because the upper teeth are less firmly anchored in the alveolar bone than are the lower ones. ${ }^{23}$ Furthermore, the temporary separation was less effective when an initial biological proximal spacing was present. A possible explanation is that the presence of pre-spacing facilitates the insertion of orthodontic rubber rings, reducing the separator action against the tight contact point.

\section{Conclusion}

The biological interdental spacing does not influence the performance of methods of detecting proximal caries lesions in primary molars. Furthermore, temporary tooth separation provides a spacing narrower than $1.0 \mathrm{~mm}$. 


\section{Acknowledgements}

The authors wish to thank the participants of the Postgraduate Studies in Pediatric Dentistry Seminar of FOUSP for the critical comments put forth. The study was supported by the Conselho Nacional de Desenvolvimento Científico e Tecnológico (CNPq

\section{References}

1. Allison PJ, Schwartz S. Interproximal contact points and proximal caries in posterior primary teeth. Pediatr Dent. 2003 Jul-Aug;25(4):334-40.

2. Marquezan M, Faraco-Junior IM, Feldens CA, Kramer PF, Ferreira SH. Association between occlusal anomalies and dental caries in 3- to 5 year-old Brazilian children. J Orthod. 2011 Mar;38(1):8-14.

3. Novaes TF, Matos R, Braga MM, Imparato JC, Raggio DP, Mendes FM. Performance of a pen-type laser fluorescence device and conventional methods in detecting approximal caries lesions in primary teeth--in vivo study. Caries Res. 2009;43(1):36-42.

4. Ekstrand KR, Bruun G, Bruun M. Plaque and gingival status as indicators for caries progression on approximal surfaces. Caries Res. 1998;32(1):41-5.

5. de Araujo FB, de Araujo DR, dos Santos CK, de Souza MA. Diagnosis of approximal caries in primary teeth: radiographic versus clinical examination using tooth separation. Am J Dent. 1996 Apr;9(2):54-6.

6. Bader JD, Shugars DA, Bonito AJ. A systematic review of the performance of methods for identifying carious lesions. $J$ Public Health Dent. 2002 Fall;62(4):201-13.

7. Celiberti P, Leamari VM, Imparato JC, Braga MM, Mendes FM. In vitro ability of a laser fluorescence device in quantifying approximal caries lesions in primary molars. J Dent. 2010 Aug;38(8):666-70.

8. Braga MM, Morais CC, Nakama RC, Leamari VM, Siqueira WL, Mendes FM. In vitro performance of methods of approximal caries detection in primary molars. Oral Surg Oral Med Oral Pathol Oral Radiol Endod. 2009 Oct;108(4):e35-41.

9. Lussi A, Hack A, Hug I, Heckenberger H, Megert B, Stich H. Detection of approximal caries with a new laser fluorescence device. Caries Res. 2006;40(2):97-103.

10. Pitts NB, Longbottom C. Temporary tooth separation with special reference to the diagnosis and preventive management of equivocal approximal carious lesions. Quintessence Int. 1987 Aug;18(8):563-73.

11. Bjarnason $S$. Temporary tooth separation in the treatment of approximal carious lesions. Quintessence Int. 1996 Apr;27(4):249-51.

12. Mialhe FL, Pereira AC, Pardi V, de Castro Meneghim M. Comparison of three methods for detection of carious lesions
- Process n. 476372/2006-2, 302368/2008-6 and 565061/2008-9), Pró-Reitoria de Pesquisa e de PósGraduação da USP, and Fundação de Amparo à Pesquisa do Estado de São Paulo (FAPESP), process n. 2009/16082-0.

in proximal surfaces versus direct visual examination after tooth separation. J Clin Pediatr Dent. 2003 Fall;28(1):59-62.

13. Seddon RP. The detection of cavitation in carious approximal surfaces in vivo by tooth separation, impression and scanning electron microscopy. J Dent. 1989 Jun;17(3):117-20.

14. Novaes TF, Matos R, Raggio DP, Imparato JC, Braga MM, Mendes FM. Influence of the discomfort reported by children on the performance of approximal caries detection methods. Caries Res. 2010;44(5):465-71.

15. Ismail AI, Sohn W, Tellez M, Amaya A, Sen A, Hasson H, et al. The International Caries Detection and Assessment System (ICDAS): an integrated system for measuring dental caries. Community Dent Oral Epidemiol. 2007 Jun;35(3):170-8.

16. Kidd EA, Fejerskov O. What constitutes dental caries? Histopathology of carious enamel and dentin related to the action of cariogenic biofilms. J Dent Res. 2004;83 Spec No C:C35-8.

17. Mejare I, Kallest $1 \mathrm{C}$, Stenlund H. Incidence and progression of approximal caries from 11 to 22 years of age in Sweden: a prospective radiographic study. Caries Res. 1999;33(2):93100.

18. Vanderas AP, Manetas C, Koulatzidou M, Papagiannoulis L. Progression of proximal caries in the mixed dentition: a 4-year prospective study. Pediatr Dent. 2003 May-Jun;25(3):229-34.

19. Ekstrand KR, Luna LE, Promisiero L, Cortes A, Cuevas S, Reyes JF, et al. The reliability and accuracy of two methods for proximal caries detection and depth on directly visible proximal surfaces: an in vitro study. Caries Res. 2011;45(2):93-9.

20. Ekstrand KR, Bakhshandeh A, Martignon S. Treatment of proximal superficial caries lesions on primary molar teeth with resin infiltration and fluoride varnish versus fluoride varnish only: efficacy after 1 year. Caries Res. 2010;44(1):416.

21. Rimmer PA, Pitts NB. Temporary elective tooth separation as a diagnostic aid in general dental practice. Br Dent J. 1990 Aug 11-25;169(3-4):87-92.

22. Deery C, Care R, Chesters R, Huntington E, Stelmachonoka $\mathrm{S}$, Gudkina Y. Prevalence of dental caries in Latvian 11- to 15 -year-Old children and the enhanced diagnostic yield of temporary tooth separation, FOTI and electronic caries measurement. Caries Res. 2000 Jan-Feb;34(1):2-7.

23. Novaes TF, Matos R, Raggio DP, Braga MM, Mendes FM. Children's discomfort in assessments using different methods 
for approximal caries detection. Braz Oral Res. 2012 MarApr;26(2):93-9.

24. Davidovitch M, Papanicolaou S, Vardimon AD, Brosh T. Duration of elastomeric separation and effect on interproximal contact point characteristics. Am J Orthod Dentofacial Orthop. 2008 Mar;133(3):414-22; quiz 76 e2.

25. Hintze H, Wenzel A, Danielsen B, Nyvad B. Reliability of visual examination, fibre-optic transillumination, and bite-wing radiography, and reproducibility of direct visual examination following tooth separation for the identification of cavitated carious lesions in contacting approximal surfaces. Caries Res. 1998;32(3):204-9.

26. Irwig LM, Bossuyt PM, Glasziou PP, Gatsonis C, Knottnerus JA. Designing studies to ensure that estimates of test accuracy will travel. In: Knottnerus JA, editors. The Evidence Base of Clinical Diagnosis. London: BMJ Books; 2002. 